\title{
DIFERENTES PRODUTOS DE SENSORIAMENTO REMOTO NO MAPEAMENTO VISUAL DE DRENAGENS E NASCENTES NA MICROBACIA HIDROGRÁFICA DO CEVEIRO
}

\author{
Raoni Wainer Duarte Bosquilia ${ }^{1}$, Peterson Ricardo Fiorio ${ }^{2}$, Sergio Nascimento Duarte ${ }^{2}$, Rafael \\ Mingoti ${ }^{3}$, Silvio Sandoval Zocchi ${ }^{2}$ \\ ${ }^{1}$ Universidade Tecnológica Federal do Paraná - UTFPR - Campus Dois Vizinhos, Brasil. E-mail: raonibosquilia@utfpr.edu.br \\ ${ }^{2}$ Universidade de São Paulo - USP/ESALQ, Brasil. E-mail: fiorio@usp.br, snduarte@usp.br, sszocchi@gmail.com \\ ${ }^{3}$ Embrapa Monitoramento por Satélite, Brasil. E-mail: ramingoti@uol.com.br
}

\section{RESUMO}

O uso de imagens de satélite e fotografias aéreas são cada vez mais comuns na obtenção de dados sobre recursos ambientais, como os cursos d'água. Deste modo, o presente trabalho objetivou comparar três diferentes produtos de Sensoriamento Remoto no mapeamento visual de drenagens e nascentes: imagens do satélite SPOT/Ikonos, imagens do programa Google Earth $^{\circledR} \mathrm{e}$ fotografias aéreas, na Microbacia Hidrográfica do Córrego do Ceveiro (MHC), localizada em Piracicaba/SP. Utilizou-se rede de drenagem presente em cartas topográficas do IGC/SP, escala 1:10.000, como base para comparação. Foram analisados dois fatores: comprimento de drenagem (CD) e número de nascentes (NN), sendo as análises realizadas apenas em caráter quantitativo. Para $\mathrm{o} C D$, o produto SPOT se mostrou mais semelhante às cartas 1:10.000, apresentando $1,43 \%$ acima do CD existente nas cartas. Para o NN, a fotografia aérea mostrou o coeficiente mais alto, sendo esse o produto analisado que apresentou maior equivalência com o valor das nascentes observadas nas cartas.

Palavras-chave: Fotografias aéreas, Google Earth, SIG, SPOT

\section{DIFFERENT REMOTE SENSING PRODUCTS IN VISUAL MAPPING OF DRAINAGES AND SPRINGS IN THE HIDROGRAPHIC MICRO BASIN OF CERVERO CREEK, IN PIRACICABA, STATE OF SÃO PAULO, BRAZIL}

\section{ABSTRACT}

The use of satellite images and aerial photography is becoming increasingly common in obtaining environmental data about natural resources, such as streams. Thus, the present study aimed to compare three different products used in the visual mapping of drainages and springs: images from SPOT/Ikonos satellite, Google Earth ${ }^{\circledR}$ images and aerial photographs, for the micro 


\section{DIFERENTES PRODUTOS DE SENSORIAMENTO REMOTO NO MAPEAMENTO VISUAL DE DRENAGENS E NASCENTES NA MICROBACIA HIDROGRÁFICA DO CEVEIRO}

basin of Ceveiro, located in Piracicaba/SP, Brazil. One used the drainage network present in the IGC topographic maps scale 1:10,000 as a basis for comparison. One analyzed two factors: length of drainage and number of springs. Analyses were performed only on quantitative character. For length of drainage, SPOT image showed greater resemblance to the 1:10,000 topographic maps, with $1.43 \%$ above the existing drainage length in these maps. To the number of springs, the aerial photographs springs showed the highest coefficient value, which is the analyzed product with the highest similarity to the value obtained from the IGC maps.

Keywords: Aerial photographs, GIS, Google Earth, SPOT

\section{INTRODUÇÃO}

A disponibilidade de recursos hídricos como um todo é limitada e sua demanda cresceu com o aumento populacional, de forma a determinar disputas pelo direito do uso da água (BOKEN et al., 2004). As principais fontes de recursos hídricos disponíveis ao sustento humano não excedem $90.000 \mathrm{~km}^{3}$ ou $0,26 \%$ da água doce da Terra (SHIKLOMANOV, 1998). Pinto et al. (2004) ressaltaram que a água potável acessível é relativamente escassa e, sem dúvida, essa escassez será um dos principais problemas ambientais enfrentados pela população mundial nas próximas décadas. Tal fato pode ser percebido conforme o Relatório das Organizações das Nações Unidas (ONU), que prevê que a água foi um recurso escasso para este milênio e, daqui a 3 décadas, a carência de água vai afetar $2 / 3$ da população mundial, o equivalente a 5,5 bilhões de pessoas (ALMEIDA et al., 2000).
Uma bacia hidrográfica pode ser definida como unidade física, caracterizada como área de terra drenada por um determinado curso d'água e limitada, perifericamente, pelo divisor de águas. Moldan \& Cerny (1994) definem uma microbacia, do ponto de vista hidrológico, como a menor unidade da paisagem capaz de integrar todos os componentes relacionados com a qualidade e disponibilidade de água como: atmosfera, vegetação natural, plantas cultivadas, solos, rochas subjacentes, corpos d'água e paisagem circundante.

Alves \& Carvalho (2007) afirmaram que, para a proteção do meio ambiente, o uso do Sistema de Informação Geográfica (SIG) tem contribuído com as metodologias empregadas em estudos ambientais oferecendo maior agilidade, objetividade, consistência e precisão na tomada de decisões geoespaciais, sobretudo a partir da década de $70 . \mathrm{O}$ processamento de 
informações geográficas, ou seja, desenvolvido em ambiente de SIG, é uma ferramenta fundamental nas análises qualitativas e quantitativas na caracterização do objeto de estudo. Para Nowatzki et al. (2010), a utilização do Sistema de Informações Geográficas (SIG) pode ser uma excelente ferramenta, visto que os mapeamentos são realizados com maior precisão e utilizados em diversos tipos de estudos.

Nesse contexto, Alves et al. (2008) mapearam as nascentes da bacia hidrográfica do Ribeirão Santa Cruz, em Lavras-MG, com base em fotos aéreas verticais para verificar a distribuição espacial de algumas variáveis ambientais nas nascentes. Os resultados obtidos mostraram que foi possível representar e caracterizar a distribuição espacial nas nascentes, sendo o Sistema de Informações Geográficas de suma importância para realização do trabalho. Neste trabalho, as fotografias foram interpretadas com o auxílio de um estereoscópio de bolso, o qual forneceu uma visão tridimensional do terreno, com base na metodologia de Rocha (1985).

Roig et al. (2009) fizeram uma avaliação bem-sucedida do uso e cobertura da terra em um área da APA da Bacia do Rio São Bartolomeu-DF utilizando imagem do satélite SPOT5, sendo que essa imagem foi importante para a melhor definição dos alvos pretendidos.

Simon \& Trentin (2009), em busca de alternativas em imagens para a elaboração de séries temporais de uso da terra, procuraram avaliar as potencialidades das imagens do programa Google Earth ${ }^{\circledR}$. Foram apresentadas duas aplicações destas imagens na identificação de padrões recentes de uso da terra e, de forma geral, as imagens do Google Earth ${ }^{\circledR}$ se mostraram adequadas para tal fim, já que no programa existiam algumas datas diferentes de imagens para os locais estudados.

Assim sendo, o objetivo do presente trabalho foi o de comparar diferentes produtos de sensoriamento remoto no mapeamento visual de drenagens $\mathrm{e}$ nascentes, utilizando cartas topográficas em escala 1:10.000 como base.

\section{MATERIAL E MÉTODOS}

A Microbacia Hidrográfica do Córrego do Ceveiro (MHC) está localizada na margem direita do Rio Piracicaba, dentro do município de Piracicaba, Estado de São Paulo (Figura 1), possuindo uma área total de $21,8 \mathrm{~km}^{2} \quad(1,56 \%$ da área total do município). Está situada entre as 
coordenadas de latitudes $22^{\circ} 37^{\prime} 00^{\prime \prime}$ S e $22^{\circ} 40^{\prime} 00^{\prime \prime} \mathrm{S}$ e de longitudes $47^{\circ} 43^{\prime} 00^{\prime \prime} \mathrm{O}$ e $47^{\circ} 47^{\prime} 00^{\prime \prime} \mathrm{O}$ e é limitada a montante pelo bairro de Santana e a jusante pelo distrito de Ártemis, sendo o referido córrego um dos afluentes diretos do Rio Piracicaba.

As cartas topográficas (planialtimétricas) têm a função de auxiliar na elaboração de diversos tipos de trabalho, como mapeamentos de declividade, mapeamento hipsométrico, ajudar interpretar o relevo de bacias, e também no mapeamento de drenagens. Tais mapas contém toda a rede de drenagem e todas as isolinhas de altimetria, auxiliando assim no mapeamento e localização de nascentes.
Foram utilizadas nesse trabalho, para compor toda a MHC, seis cartas topográficas na escala 1:10.000 confeccionadas pelo Instituto Geográfico e Cartográfico (IGC) do Estado de São Paulo.

As cartas foram digitalizadas e inseridas em programa em ambiente SIG, georreferenciadas por meio dos pontos de controle presentes, reprojetadas para o DATUM SIRGAS 2000 e assim obteve-se digitalizadas todas as suas curvas de nível (incluindo os pontos cotados) e hidrografia (Figura 5), para que fosse possível mapear e quantificar o número de nascentes presentes nas cartas para assim poderem ser comparadas com os métodos estudados.

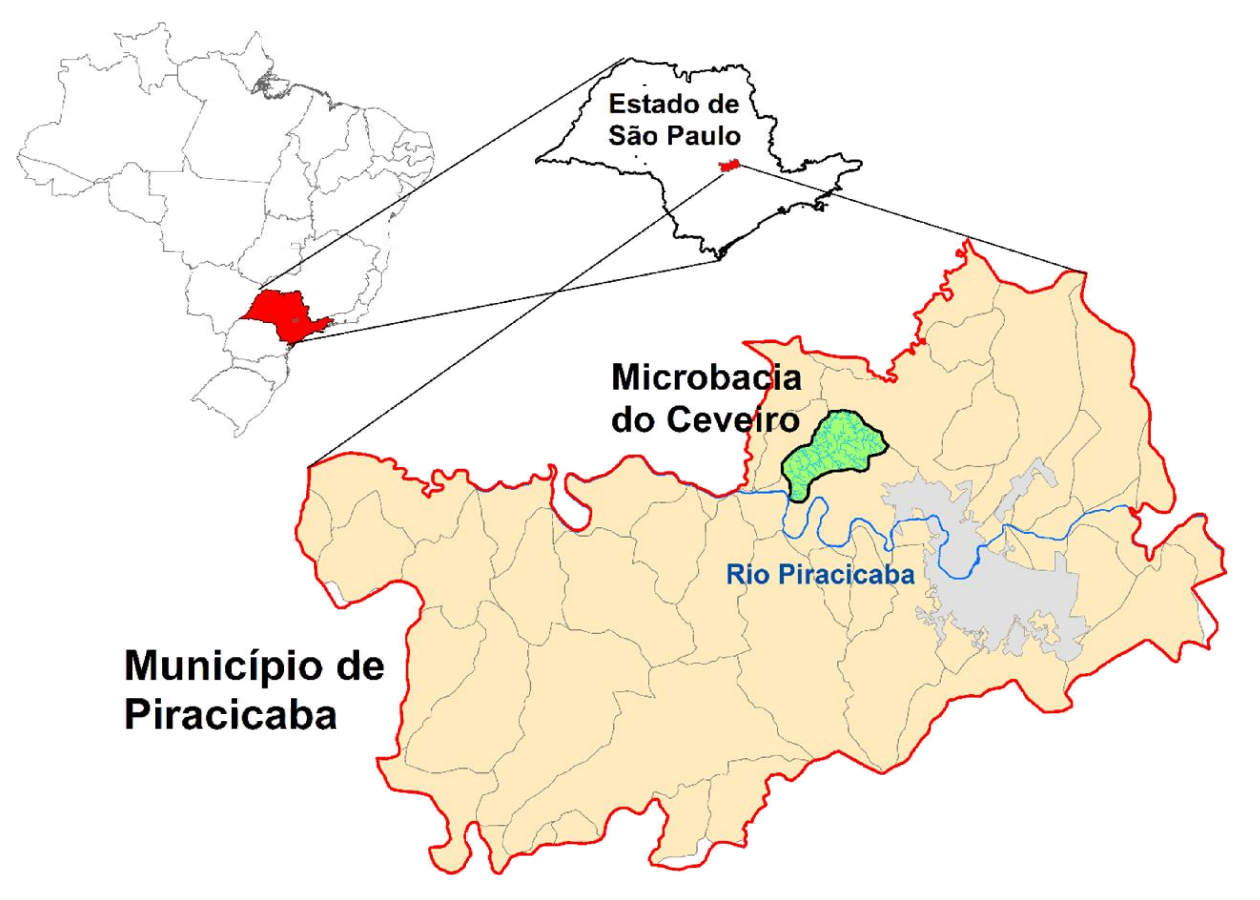

Figura 1. Localização da Microbacia Hidrográfica do Ceveiro (MHC). 
Utilizando as nascentes obtidas através das cartas topográficas do IGC 1:10.000, realizou-se uma checagem de campo a fim de confirmar a existência e localização dessas nascentes. Das 128 nascentes presentes nas cartas, locou-se 63 delas no mapa de campo (aproximadamente $50 \%$ do total de nascentes).

Para a confecção do mapa de drenagem da Microbacia Hidrográfica do Ceveiro (MHC), foram utilizadas Fotografias Aéreas da região, todas de um voo realizado no ano de 2005. Assim, com o auxílio de um estereoscópio de espelho, cada par fotográfico foi utilizado para se marcar os pontos de controle e traçar a rede hidrográfica em acetato. $\mathrm{O}$ acetato com a rede de drenagem foi digitalizado e importado para o ambiente SIG, registrando via tela tendo como referência as cartas 1:10.000 do IGC e digitalizando em vetores. Todos os mapas gerados nesse trabalho foram transformados para o DATUM SIRGAS 2000. Assim, com o mapa da rede de drenagem confeccionado, obteve-se as nascentes presentes nas fotografias aéreas da área da MHC e comparou-se os resultados, estatisticamente, através do coeficiente de correlação de concordância proposto por Lin (1989), com a metodologia considerada padrão para ser comparada neste trabalho (cartas topográficas 1:10.000).

No presente trabalho foi utilizado um mosaico de imagens do satélite francês SPOT 5 do ano de 2010 (Figura 2), com 5 metros de resolução espacial e com uma composição em cor natural RGB e um fusionamento com a banda PAN já realizada.

Como algumas áreas dessas imagens SPOT apresentaram alto índice de nuvens, utilizaram-se recortes de imagens Ikonos, com 1 metro de resolução espacial na imagem fusionada, para compor a imagem. Esse mosaico de imagens SPOT foi importado ao ambiente SIG e convertido para o DATUM SIRGAS 2000. Assim, com esse mosaico de imagens, também foi feito o mapeamento dos cursos d'água e das nascentes pelo método de vetorização em tela para posterior comparação com o resultado das cartas.

Também, com a grande facilidade de acesso da sociedade ao Google Earth $^{\circledR}$, resolveu-se realizar o mapeamento das drenagens e nascentes no próprio software Google Earth ${ }^{\circledR}$, pelo método da digitalização da imagem em tela. Posteriormente, as drenagens e nascentes foram exportadas para arquivos KMZ e importados para ambiente SIG para finalização do mapa de drenagens e nascentes e comparação com as cartas. 
A imagem utilizada no programa na região estudada é proveniente do catálogo de imagens da DigitalGlobe ${ }^{\circledR}$, obtida através do sensor QuickBird 2 (fusionada com banda pancromática) (Figura 3), com data de obtenção 09 de agosto de 2005, possuindo uma resolução espacial original considerada alta (0,61 metros), ou seja, com uma alta capacidade de se observar o alvo pretendido.

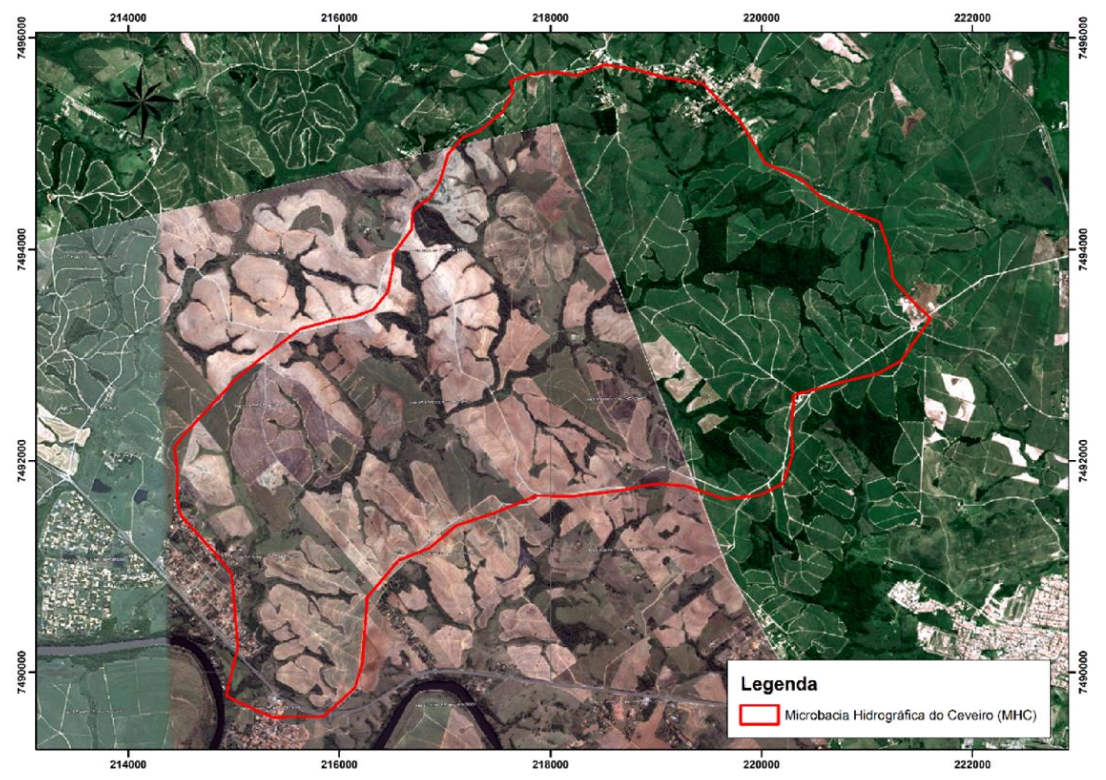

Figura 2. Mosaico de imagens fusionadas do satélite SPOT 5 e Ikonos para a Microbacia do Ceveiro (MHC).

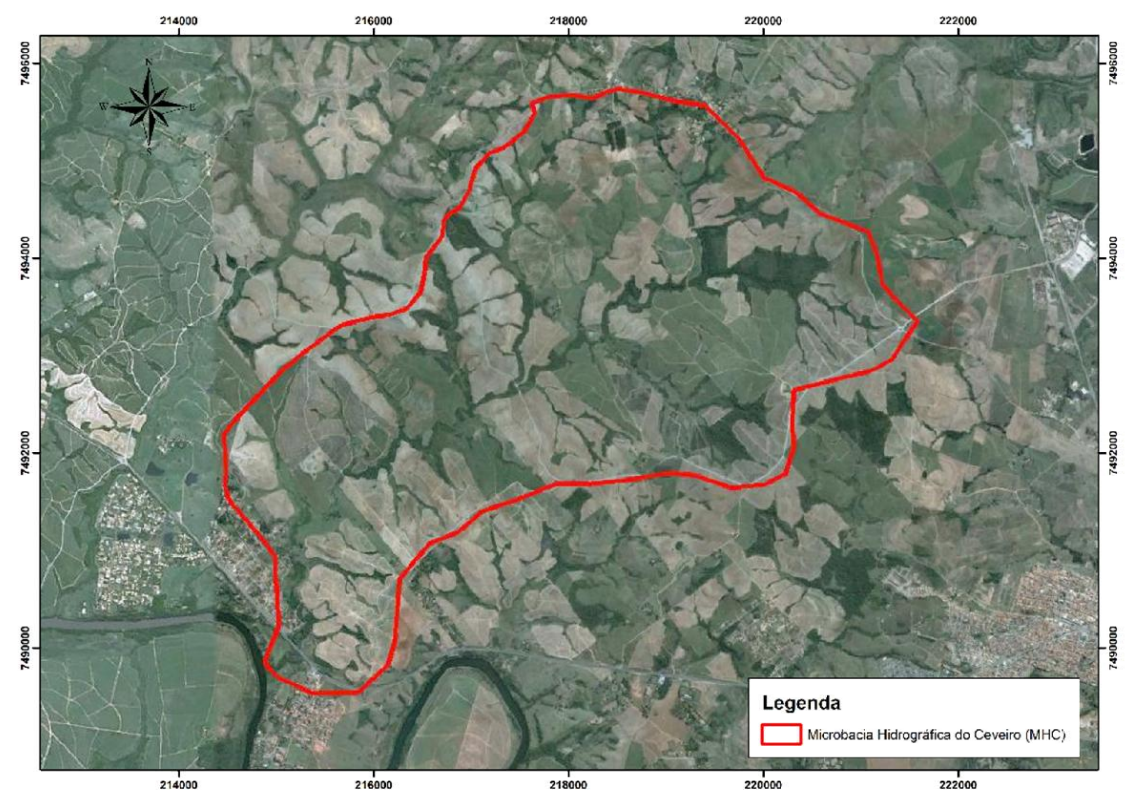

Figura 3. Imagem do Google Earth ${ }^{\circledR}$ para a Microbacia do Ceveiro (MHC). 
A metodologia aplicada está 5), cada uma com $0,785 \mathrm{~km}^{2}$ de área, representada no fluxograma das etapas de trabalho presente na Figura 4.

Conforme fluxograma (Figura 4), no presente trabalho pretende-se verificar a possível diferença no mapeamento de drenagens e nascentes utilizando fotografias aéreas e imagens de satélite de diferentes resoluções espaciais com as cartas topográficas do IGC 1:10.000.

Para ser possível uma amostragem e uma análise estatística, foram dispostas 29 amostras circulares de $0,5 \mathrm{~km}$ de raio (Figura totalizando $18,43 \mathrm{~km}^{2}$ dentro da MHC (86,12\% da área total da MHC).

Para melhor comparação entre os métodos, foram analisados dois fatores quantitativos: Comprimento das Drenagens (CD) e Número de Nascentes (NN).

Para o parâmetro CD, também estudado por Petsch et al. (2012), Fernandes et al. (2012) e Reckziegel \& Robaina (2006), obteve-se o valor de toda a MHC (e não em cada amostra circular) para ser possível uma avaliação prévia dos métodos estudados.

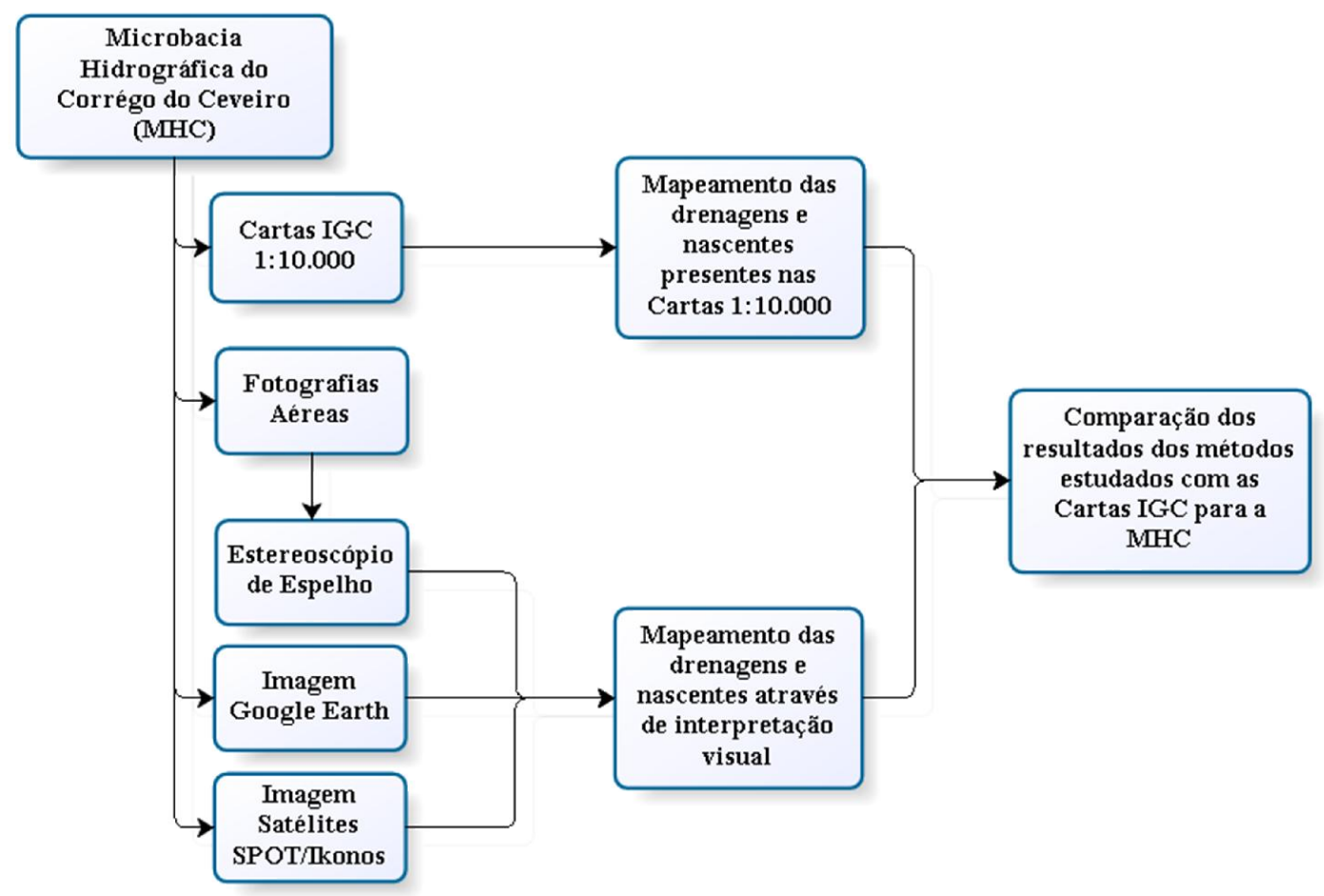

Figura 4. Fluxograma geral do trabalho: mapeamento manual (visual) dos cursos d'água e nascentes da MHC utilizando diferentes produtos. 


\section{DIFERENTES PRODUTOS DE SENSORIAMENTO REMOTO NO MAPEAMENTO VISUAL DE DRENAGENS E NASCENTES NA MICROBACIA HIDROGRÁFICA DO CEVEIRO}

Já para o NN, utilizou-se o coeficiente de correlação de concordância proposto por Lin (1989) aplicado às 29 amostras circulares. Este coeficiente foi criado especialmente para verificar se metodologias diferentes de quantificação de substâncias são equivalentes. Em seu trabalho, Lin (1989) mostrou que sua metodologia é superior a métodos como: o da comparação de médias; o da regressão linear e o do coeficiente de correlação linear de Pearson.

Assim, resolveu-se aplicar tal coeficiente para que pudesse ser realizada a análise dos resultados quantitativos finais de comparação do parâmetro NN entre os três produtos analisados e as cartas topográficas.
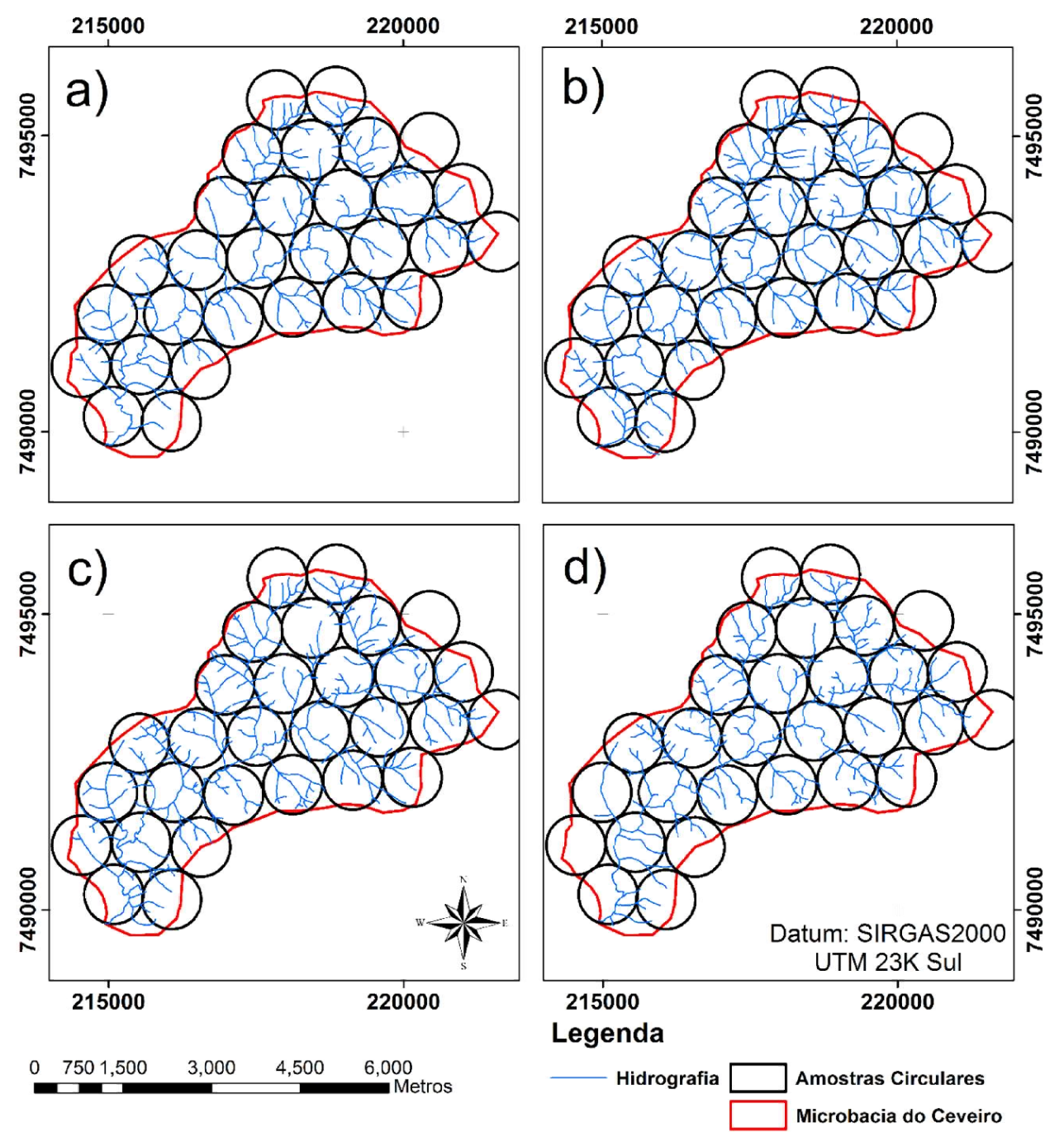

Figura 5. Amostras circulares realizadas para cada método analisado: (a) (a) Cartas Topográficas IGC; (b) Fotografias aéreas; (c) Imagem Google Earth ${ }^{\circledR}$; (d) Imagem Satélite SPOT 5/Ikonos. 


\section{RESULTADOS E DISCUSSÃO}

$\mathrm{Na}$ checagem de campo, das 63 nascentes propostas, 33 foram encontradas, mesmo que, às vezes, bem distantes do local previamente obtido nas cartas topográficas 1:10.000 (que foram elaboradas em 1978); 14 delas não foram encontradas, nem próximas, do local indicado; em 16 delas não foi possível ter acesso ao local. Ainda, foi encontrada uma outra nascente, não indicada no mapa original, que foi alocada no mapa final de checagem de campo.

Pelo fato da MHC apresentar 67,9\% do seu uso e ocupação do solo com a monocultura da cana-de-açúcar (BARROS et al., 2012), a maior parte das nascentes encontraram-se deslocadas do local originalmente proposto pelas cartas, principalmente pelo fato desta monocultura contribuir na retração da mata ciliar ao redor dessas nascentes (MACHI \& CUNHA, 2007). Assim, com essa dificuldade encontrada em campo, resolveu-se utilizar as cartas topográficas 1:10.000 sem nenhuma alteração como base para a comparação com os outros métodos, já que estas são documentos oficiais utilizados por vários órgãos públicos do Estado de São Paulo.

Deste modo, realizou-se o mapeamento dos cursos d'água presentes na Microbacia Hidrográfica do Ceveiro por meio de vetorização em tela em ambiente SIG para os três produtos analisados. Os valores de Comprimento de Drenagem (CD) obtidos através de cada produto estão apresentados na Tabela 1. Interpretando-se os resultados de $\mathrm{CD}$, observa-se que as drenagens obtidas por intermédio da imagem do satélite SPOT 5 apresentaram resultados muito semelhantes ao das cartas, tendo superestimado o comprimento dos cursos d'água em apenas $1,43 \%$. Os outros dois produtos estudados (fotografias aéreas e Google Earth $^{\circledR}$ ) superestimaram mais o comprimento de drenagem.

Tabela 1. Comprimento de Drenagem (CD) da MHC para cada produto estudado.

\begin{tabular}{ccc}
\hline Métodos & Comprimento de Drenagem (m) & Comparação com as cartas (\%) \\
\hline Cartas & $74.265,821$ & 100,00 \\
Fotografia aérea & $92.533,105$ & 124,43 \\
Google Earth $^{\circledR}$ & $89.459,624$ & 120,30 \\
SPOT 5/Ikonos & $75.427,569$ & 101,43 \\
\hline
\end{tabular}




\section{DIFERENTES PRODUTOS DE SENSORIAMENTO REMOTO NO MAPEAMENTO VISUAL DE DRENAGENS E NASCENTES NA MICROBACIA HIDROGRÁFICA DO CEVEIRO}

Para as fotografias aéreas, houve um acréscimo de $24,43 \%$ do comprimento total presente nos cursos d'água extraído das cartas. Já para o Google Earth ${ }^{\circledR}$, houve um acréscimo ligeiramente menor, de 20,30\% do total presente nas cartas. Esse resultado muito semelhante de CD obtido através da imagem do satélite SPOT 5/Ikonos com as cartas é de que essa imagem possui uma resolução espacial média, fazendo com que alguns detalhes não sejam detectados, quando comparada à imagem do Google Earth $^{\circledR}$ e às fotografias aéreas, que são produtos com maior riqueza de detalhes, diferenciando-se mais das cartas.

Outro fator que pode ser considerado é de que a imagem SPOT data do ano de 2010, enquanto as imagens do Google Earth $^{\circledR}$ e as Fotografias Aéreas são datadas de 2005. Assim, pode ser possível que tenha havido alguma alteração no ambiente durante esses anos, reduzindo o $\mathrm{CD}$ com a retração das nascentes e das matas ciliares.

Quanto ao Número de Nascentes (NN), obteve-se as nascentes das 29 amostras circulares propostas para esse parâmetro (Figura 6), para os três produtos estudados (Tabela 2).
Analisando os resultados (Tabela 2), observou-se que os três produtos estudados se aproximaram dos valores de $\mathrm{NN}$ presentes nas cartas, para a grande maioria das amostras circulares.

O resultado obtido corrobora com o trabalho realizado por Viel et al. (2013), que mapearam nascentes através das imagens do Google Earth $^{\circledR}$ em Monte Belo do Sul/RS com êxito, checando-as em campo posteriormente e concluindo que foi possível realizar o mapeamento de nascentes através de imagens de satélite.

Assim, aplicou-se o coeficiente de correlação de concordância proposto por Lin (1989) ao resultado de NN das 29 amostras circulares (Figura 7), verificando se os coeficientes observados nos resultados de $\mathrm{NN}$ entre as cartas topográficas do IGC e os três produtos utilizados na interpretação visual, e respectivos intervalos de $95 \%$ de confiança. Analisando-se a mesma, observase que em nenhum dos produtos estudados o intervalo de confiança incluiu o valor 0 , ou seja, quando não se há evidências para dizer que essas metodologias são equivalentes à padrão. 

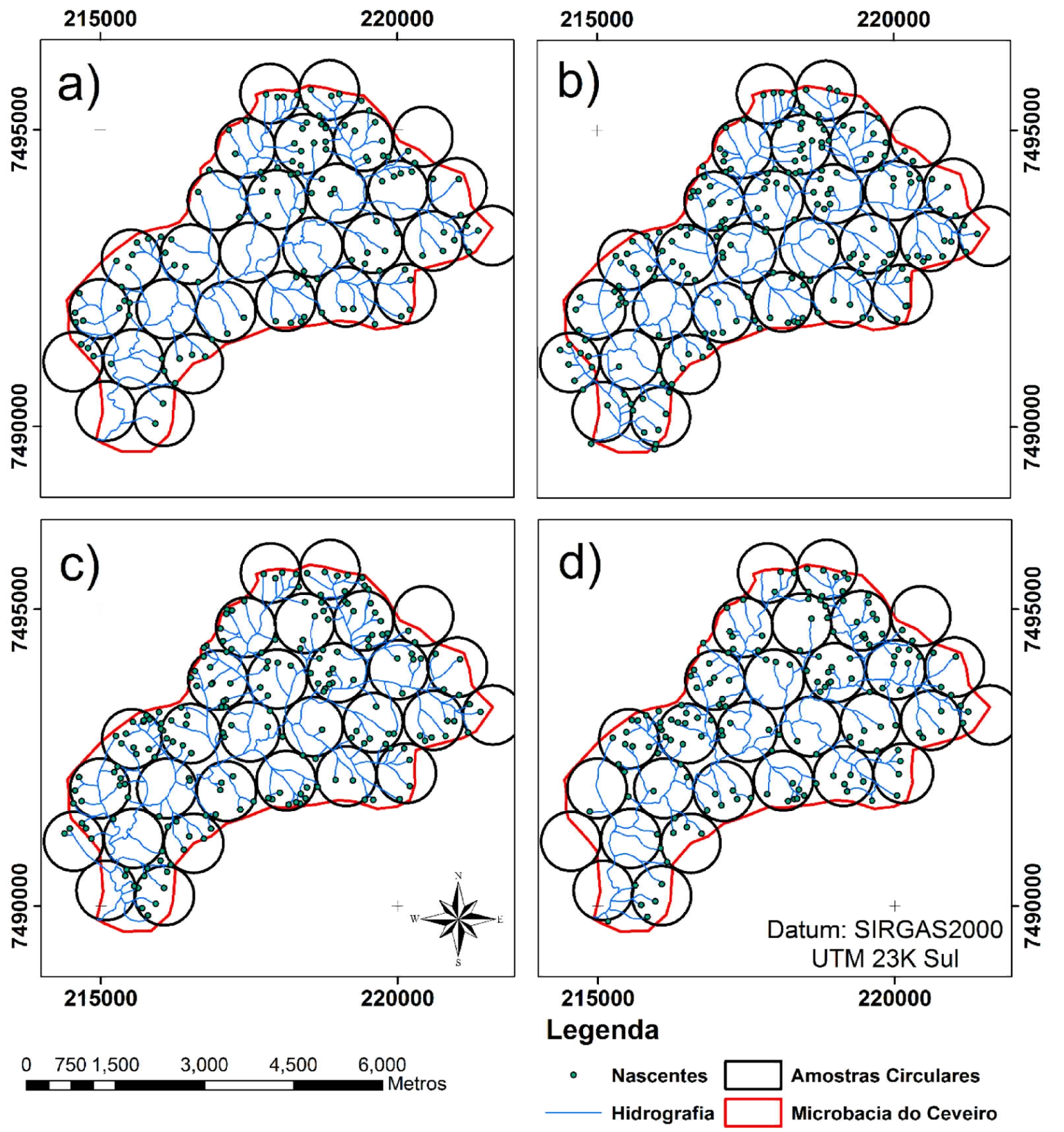

Figura 6. Amostras circulares dispostas sobre a MHC para a aplicação do coeficiente de correlação de concordância de Lin para o Número de Nascentes (NN): (a) Cartas Topográficas IGC; (b) Fotografias aéreas; (c) Imagem Google Earth ${ }^{\circledR}$; (d) Imagem Satélite SPOT 5. 
Tabela 2. Número de Nascentes $(\mathrm{NN})$ na $\mathrm{MHC}$ obtido por cada produto de sensoriamento remoto para cada amostra circular.

\begin{tabular}{|c|c|c|c|c|}
\hline Amostras Circulares & Cartas IGC & Fotografia aérea & SPOT 5 & Google Earth $^{\circledR}$ \\
\hline 1 & 0 & 4 & 4 & 5 \\
\hline 2 & 2 & 5 & 6 & 6 \\
\hline 3 & 4 & 6 & 4 & 6 \\
\hline 4 & 2 & 1 & 1 & 1 \\
\hline 5 & 0 & 1 & 3 & 3 \\
\hline 6 & 5 & 9 & 13 & 10 \\
\hline 7 & 6 & 8 & 9 & 12 \\
\hline 8 & 6 & 6 & 1 & 8 \\
\hline 9 & 3 & 9 & 0 & 5 \\
\hline 10 & 0 & 2 & 0 & 3 \\
\hline 11 & 2 & 7 & 5 & 7 \\
\hline 12 & 6 & 7 & 7 & 9 \\
\hline 13 & 2 & 12 & 10 & 12 \\
\hline 14 & 6 & 8 & 3 & 6 \\
\hline 15 & 1 & 2 & 2 & 1 \\
\hline 16 & 3 & 4 & 6 & 2 \\
\hline 17 & 4 & 7 & 7 & 8 \\
\hline 18 & 7 & 9 & 6 & 8 \\
\hline 19 & 4 & 5 & 4 & 5 \\
\hline 20 & 4 & 7 & 4 & 6 \\
\hline 21 & 4 & 9 & 11 & 12 \\
\hline 22 & 11 & 14 & 6 & 7 \\
\hline 23 & 4 & 6 & 8 & 5 \\
\hline 24 & 3 & 4 & 4 & 4 \\
\hline 25 & 3 & 3 & 2 & 2 \\
\hline 26 & 7 & 7 & 12 & 11 \\
\hline 27 & 5 & 6 & 8 & 6 \\
\hline 28 & 4 & 4 & 3 & 4 \\
\hline 29 & 2 & 2 & 2 & 2 \\
\hline
\end{tabular}




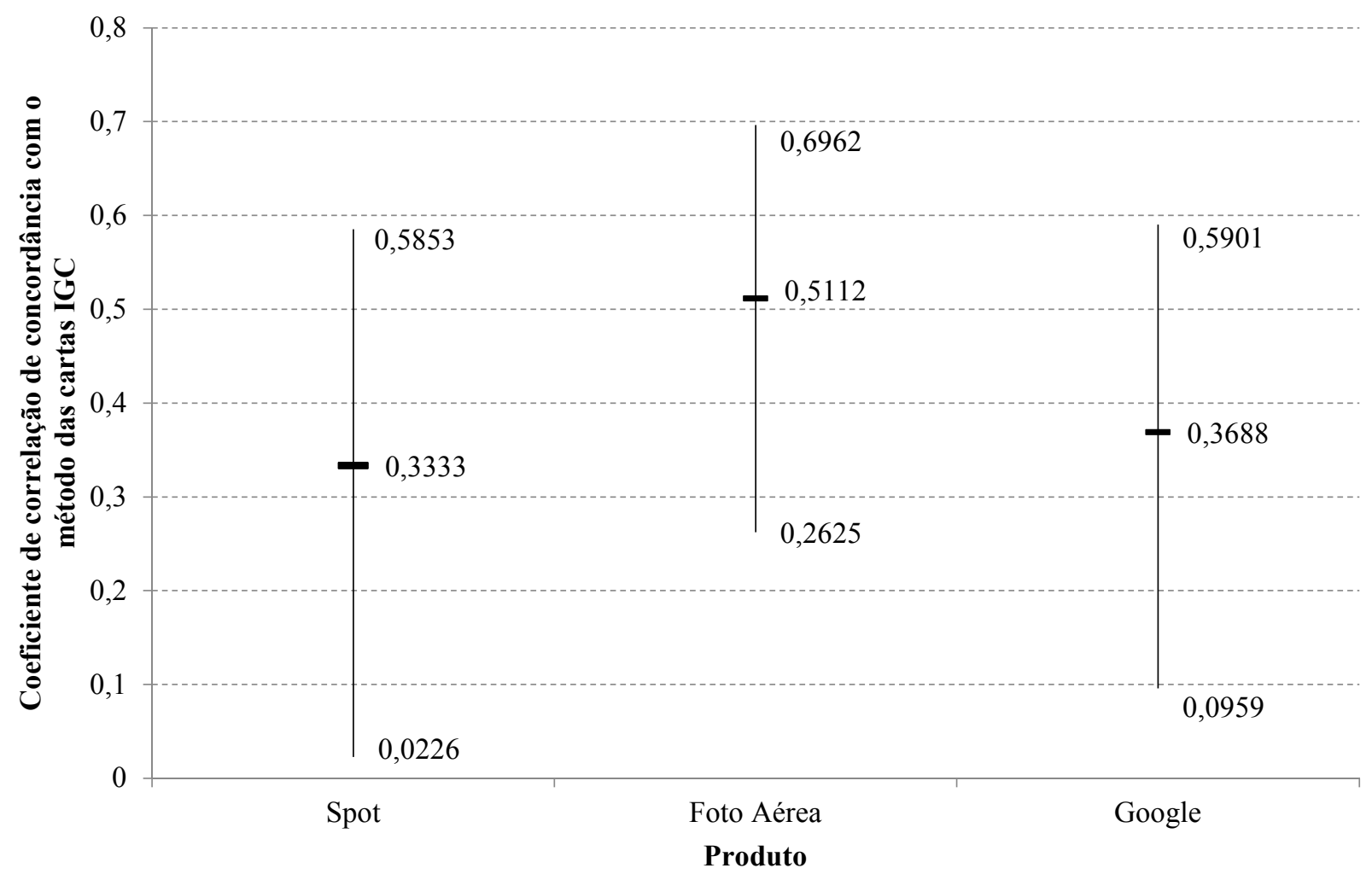

Figura 7. Coeficientes de correlação de concordância (-) para o parâmetro NN entre as cartas topográficas do IGC e os três produtos de sensoriamento remoto e seus respectivos intervalos de $95 \%$ de confiança.

Sendo assim, as nascentes obtidas através das imagens SPOT e do Google Earth $^{\circledR}$ apresentaram coeficientes de correlação de concordância 0,33 e 0,37 , significativamente diferentes de 0 (nível de significância 5\%), respectivamente, porém com valores que podem ser considerados baixos, segundo literatura (LIN, 1989; ZAR, 1999).

O produto analisado que apresentou a maior equivalência do $\mathrm{NN}$ com as cartas topográficas foi o da fotografia aérea, com coeficiente 0,51 , também significativo e mais elevado que os demais, sendo esse método considerado o mais eficiente estudado na obtenção do NN.

Com o resultado de $\mathrm{NN}$ para cada amostra, elaborou-se gráficos de dispersão (Figura 8) das 29 amostras circulares comparando os resultados obtidos pelos três diferentes produtos às nascentes existentes nas cartas (Tabela 2). 


\section{DIFERENTES PRODUTOS DE SENSORIAMENTO REMOTO NO MAPEAMENTO VISUAL DE DRENAGENS E NASCENTES NA MICROBACIA HIDROGRÁFICA DO CEVEIRO}
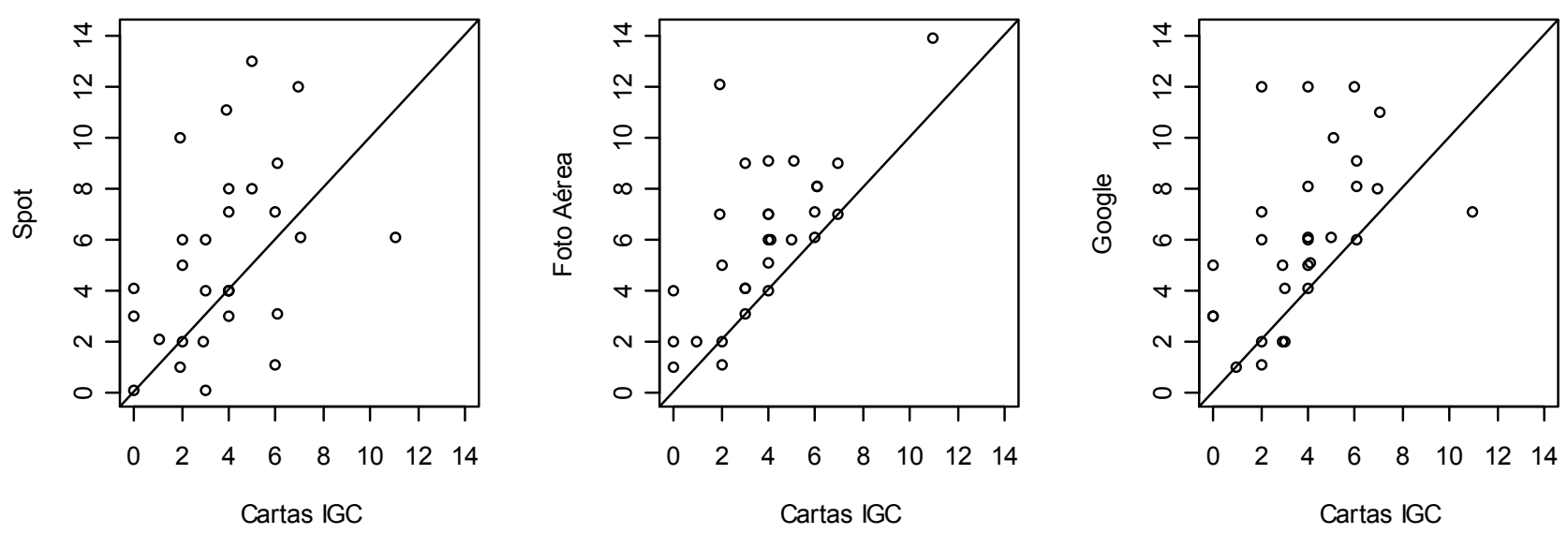

Figura 8. Gráficos de dispersão e da reta de equação $\mathrm{y}=\mathrm{x}$ dos três produtos utilizados na interpretação visual de nascentes.

Observou-se (Figura 8) que os resultados obtidos pelas fotografias aéreas se aproximaram mais da reta de equação $\mathrm{y}=\mathrm{x}$ do que os dois outros produtos, ou seja, o número de nascentes nas amostras circulares para o as fotografias se aproximou mais do observado nas cartas do que pelas imagens SPOT e Google Earth ${ }^{\circledR}$ (Tabela 2).

Também, pela análise da Figura 8 e da Tabela 2, observou-se que a imagem do satélite SPOT apresentou, em 8 das 29 amostras, um resultado de $\mathrm{NN}$ menor do que as cartas; isso foi causado pela menor resolução espacial desse produto, fazendo com que menos objetos fossem observados (CRÓSTA, 1992).

Assim, interpretando-se os resultados de $\mathrm{NN}$, foi possível concluir que, para quantificar o número de nascentes em uma bacia, os três produtos analisados podem ser considerados como possíveis de se obter esse parâmetro, já que a estatística mostrou que os mapas de nascentes obtidos por cada método não foram, estatisticamente, diferentes das cartas.

\section{CONCLUSÕES}

Os produtos de sensoriamento remoto analisados no mapeamento visual de drenagens e nascentes apresentaram resultados, quantitativamente, para ambos os parâmetros estudados (CD e NN), semelhantes às cartas topográficas IGC escala 1:10.000, sendo esses produtos adequados para uso em áreas onde não se possua nenhuma carta topográfica com escala semelhante à utilizada nesse estudo, servindo como métodos alternativos na elaboração de mapas hidrológicos e de 
mapas de nascentes para os mais variados trabalhos, inclusive para aceitação de órgãos públicos que utilizam cartas topográficas como referência.

Para o CD, a imagem do satélite SPOT apresentou maior semelhança com as cartas 1:10.000, apresentando apenas 1,43\% acima do CD existente nas cartas.

Para o NN, houve maior semelhança entre os produtos estudados, tendo a fotografia aérea apresentado o valor mais alto do coeficiente, sendo esse o produto analisado que apresentou maior equivalência com o valor das nascentes obtidas nas cartas.

\section{REFERÊNCIAS}

ALMEIDA, D.S.; DUARTE, A.J.; ARAÚJO, R.P. 2000. Projeto de recuperação de matas ciliares e nascentes da bacia do Rio dos Mangues. In: CONGRESSO DE EXPOSIÇÃO INTERNACIONAL SOBRE FLORESTAS, 6., Porto Seguro. Anais... Rio de Janeiro. p.575-576.

ALVES, T.M.; CARVALHO, T.M. 2007. Técnicas de sensoriamento remoto para classificação e quantificação do sistema lacustre do rio Araguaia entre Barra do Garças e foz do rio Cristalino. Revista Geográfica Acadêmica, Goiânia, UFG, v. 1, p.79-94.

ALVES, M.C.; BOTELHO, S.A.; PINTO, L.V.A.; POZZA, E.A.; de OLIVEIRA, M. S., FERREIRA, E., ANDRADE, H. 2008. Variabilidade espacial de variáveis geobiofísicas nas nascentes da bacia hidrográfica do Ribeirão Santa Cruz. Revista Brasileira de Engenharia Agrícola e Ambiental, Campina Grande, v.12, n.5, p.527-535.

BARROS, P. P. S.; FIORIO, P. R.; OLIVEIRA, J. S.; BOSQUILIA, R. W. D. 2012. Comparação entre o uso e ocupação, nos anos de 1995 e 2010, na Microbacia Hidrográfica do Ceveiro, Piracicaba - SP. In: IV Workshop sobre a Utilização de SIG na Análise Ambiental, 2012, Piracicaba - SP. Anais... Piracicaba. p.55-61.

BOKEN, V.K.; HOOGENBOOM, G.; HOOK, J.E.; THOMAS, D.L.; GUERRA, L.C.; HARRISON, K. A. 2004. Agricultural water use estimation using geospatial modeling and a geographic information system. Agricultural Water Management, Amsterdam, v.67, n.3, p.185-189.

CRÓSTA, A.P. 1992. Processamento digital de imagens de sensoriamento remoto. Campinas, IG/UNICAMP. 164p.

FERNANDES, M.C.; AVELAR, A.S.; MENEZES, P.M.L.; COELHO-NETTO, A.L. 2012. Comparação do uso de superfície real e planimétrica para análises do índice de eficiência de drenagem: um estudo de caso no Maciço da Tijuca - RJ. Revista Brasileira de Geomorfologia, Uberlândia, v.13, n. 1, p. $29-37$.

LIN, L.I-K. 1989. A concordance correlation coefficient to evaluate reproducibility. Biometrics, Washington, v. 45, p. 255-268.

MACHI, D.A.; CUNHA, C.M.L. da. 2007. Caracterização dos elementos físicos da bacia do córrego Santo Antônio (Rio Claro/SP). Revista Sociedade \& Natureza, Uberlândia, v.19, n.2, p. 139-151.

MOLDAN, B.; CERNY, J. 1994. Small catchment research. In: Biogeochemistry of small catchment: a tool for environmental research. Chicester: John Wiley. p. 1-29.

NOWATZKI, A.; SANTOS, L.J.C.; de PAULA, E.V. 2010. Utilização do Sig na Delimitação das Áreas de Preservação 
Permanente (APP's) na Bacia do Rio Sagrado (Morretes/PR). Revista Sociedade \& Natureza, Uberlândia, v.22, n. 1, p.107120 .

PETSCH, C.; MONTEIRO, J.B.; BUENO, M.B. 2012. Análise comparativa da acuracidade da rede de drenagem gerada automaticamente e extraída de carta topográfica estudo de caso no município de Ponta Grossa - PR. Revista Geonorte, Manaus, v.2, n.4, p.1195-1205.

PINTO, L.V.A.; BOTELHO, S.A.; DAVIDE, A.C.; FERREIRA, E. 2004. Estudo das nascentes da bacia hidrográfica do Ribeirão Santa Cruz, Lavras, MG. Scientia Forestalis, Piracicaba, n. 65, p. 197-206.

RECKZIEGEL, E.W.; ROBAINA, L.E.S. 2006. Estudo de parâmetros morfométricos do relevo e da rede de drenagem da área situada entre os rios Jaguari e Ibicuí no município de São Vicente do Sul - RS. In: SIMPÓSIO NACIONAL DE GEOMORFOLOGIA, 6, 2006.. Anais... Goiânia: UFGO. On-line. Disponível em: $<$ www.ufsm.br/lageolam/arquivos/Reckzieg el_E.pdf $>$. Acesso em: 07 nov. 2013.

ROCHA, J.S.M. 1985. Manual de interpretação de aerofotogramas. 2.ed. Santa Maria: UFSM. 83p.

ROIG, H.L.; BAYMA, A.P.; SOARES NETO, G.B.; MENEZES, P.H.B.J.; SANTOS, R.P. 2009. Adequação de uma área situada na APA de São Bartolomeu-DF à legislação ambiental. In: SIMPÓSIO DE SENSORIAMENTO REMOTO, 14., 2009, Natal. Anais... Natal. p.6133-6140.

SHIKLOMANOV, I.A. 1998. World water resources: A new appraisal and assessment for the 21st Century. Paris:UNESCO-IHP Publication, UNESCO. 38p.

SIMON, A.L.H.; TRENTIN, G. 2009. Elaboração de cenários recentes de uso da terra utilizando imagens do Google Earth.
Ar@cne. Revista electrónica de recursos en Internet sobre Geografía y Ciencias Sociales. Barcelona: Universidad de Barcelona, $\mathrm{n}^{\mathbf{o}}$ 116. Disponível em: $<$ http://www.ub.es/geocrit/aracne/aracne116.htm>. Acesso em: 03 Out. 2013.

VIEL，J.; ARRUDA， D.C.; BERRETA, M.S.R.; FANTIN, M.L.; FARIAS, A.R.; HOFF, R. 2013. Geotecnologias e aprendizagem espacial em ambiente educacional: o mapeamento de nascentes utilizando técnicas de geoprocessamento por meio de softwares livres. In: SIMPÓSIO DE SENSORIAMENTO REMOTO,16., 2013, Foz do Iguaçu, PR. Anais... Foz do Iguaçu. p. 2650-2656.

ZAR, J.H. 1999. Biostatistical analysis. 5 ed. New Jersey: Prentice-Hall. 944p.

Recebido em:14\7\2015 Aceito para publicação em:12 $\backslash 1 \backslash 2016$ 